\title{
Terbium and Tungsten Co-doped Bismuth Oxide Electrolytes for Low Temperature Solid Oxide Fuel Cells
}

\author{
Doh Won Jung, Kang Taek Lee ${ }^{*, \dagger}$, and Eric D. Wachsman***it \\ Samsung Advanced Institute of Technology, Yongin 446-712, Republic of Korea \\ *Department of Energy Systems Engineering, DGIST (DaeguGyeongbuk Institute Science and Technology), \\ Daegu 711-873, Republic of Korea \\ **University of Maryland Energy Research Center, University of Maryland, College Park, MD 20742, USA
}

(Received June 12, 2014; Revised June 29, 2014; Accepted June 30, 2014)

\begin{abstract}
We developed a novel double dopant bismuth oxide system with Tb and $\mathrm{W}$. When Tb was doped as a single dopant, a Tb dopant concentration more than $20 \mathrm{~mol} \%$ was required to stabilize bismuth oxides with a high conductivity cubic structure. High temperature XRD analysis of $25 \mathrm{~mol} \% \mathrm{~Tb}$-doped bismuth oxide (25TSB) confirmed that the cubic structure of 25TSB was retained from room temperature to $700^{\circ} \mathrm{C}$ with increase in the lattice parameter. On the other hand, we achieved the stabilization of high temperature cubic phase with a total dopant concentration as low as $\sim 12$ mol\% with 8 mol\% Tb and 4 mol\% W double dopants (8T4WSB). Moreover, the measured ionic conductivity of 10T5WSB was much higher than 25TSB, thus demonstrating the feasibility of the double dopant strategy to develop stabilized bismuth oxide systems with higher oxygen ion conductivity for the application of SOFC electrolytes at reduced temperature. In addition, we investigated the long-term stability of TSB and TWSB electrolytes.
\end{abstract}

Key words : Solid oxide fuel cells, Electrolytes, Bismuth oxides, Double dopants

\section{Introduction}

S olid oxide fuel cells (SOFCs) are highly efficient and ecofriendly energy conversion devices. ${ }^{1,2)}$ The major obstacles to the commercialization of this fascinating technology are high system cost and rapid performance-degradation due to high operation temperature $\left(>800^{\circ} \mathrm{C}\right){ }^{1)}$ Thus, lowering the operation temperature of SOFCs can considerably reduce the system cost due to the utilization of a wider range of cheap and high-performance materials. System stability can also be improved due to the increased thermomechanical strength and slow degradation kinetics at reduced temperature. ${ }^{3,4)}$

However, as the temperature decreases, the ionic conduction in electrolytes and electrochemical reactions in electrodes, which are major mechanistic steps of SOFC operation, are dramatically slowed down due to their thermally activated nature, thus deteriorating the overall SOFC performance.,5) Therefore, the development of electrolytes with higher conductivityis of critical importance to achieve high-performance SOFCs that can operate at reduced temperature.

\footnotetext{
'Corresponding author: Kang Taek Lee

E-mail : ktlee@dgist.ac.kr

Tel : +82-53-785-6430 Fax : +82-53-785-6409

${ }^{\dagger}$ Corresponding author : Eric D. Wachsman

E-mail : ewach@umd.edu

Tel : +1-301-405-8193 Fax : +1-301-314-8514
}

In this respect, bismuth oxides with a cubic structure $(\delta$ $\mathrm{Bi}_{2} \mathrm{O}_{3}$ ) are attractive due to their highest oxygen ion conductivity among fluorite oxides. ${ }^{6-9)}$ The conductivity of $\delta-\mathrm{Bi}_{2} \mathrm{O}_{3}$ below $800^{\circ} \mathrm{C}$ is more than 100 times higher than that of yttria stabilized zirconia (YSZ), which is the most prevalent SOFC electrolyte material. ${ }^{10)}$ This high conductivity of $\delta$ $\mathrm{Bi}_{2} \mathrm{O}_{3}$ is primarily attributed to its intrinsic oxygen vacancies of $25 \%$. However, there exists only a narrow stability window of this cubic phase $\left(730-824^{\circ} \mathrm{C}\right)$, limiting its application in practical SOFC systems. ${ }^{11)}$ To overcome this issue, Takahashi et al. reported stabilization of the high temperature cubic phase of bismuth oxides by doping with lanthanides. ${ }^{12)}$ Verkerk et al. found that the highest ionic conductivity among the stabilized bismuth oxides with a single dopant was obtained by doping with $\mathrm{Er}^{3+}$ (20 mol\%) due to the lowest dopant concentration for the stabilization of $\delta$ $\mathrm{Bi}_{2} \mathrm{O}_{3}{ }^{13,14)}$ Later, a double dopant strategy was developed to stabilize the cubic $\delta-\mathrm{Bi}_{2} \mathrm{O}_{3}$ structure, and several doubly doped $\mathrm{Bi}_{2} \mathrm{O}_{3}$ electrolyte systems have been studied. ${ }^{15-17)}$ Compared to single dopant stabilization, double-dopant doping allows a much lower total dopant concentration to stabilize the fluorite phase down to room temperature due to a significant increase in entropy. ${ }^{16)}$ Recently, Wachsman et al. developed a novel doubly doped bismuth oxide system with Dy and W (DWSB). ${ }^{8,17-19)}$ In these studies, the minimum dopant concentration required to stabilize the cubic phase was reduced by $12 \mathrm{~mol} \%$ (8 mol\% Dy and $4 \mathrm{~mol} \% \mathrm{~W}, 8 \mathrm{D} 4 \mathrm{WSB}) .{ }^{17}$ ) With 8D4WSB, the highest ionic conductivity was achieved (e.g., $0.57 \mathrm{~S}-\mathrm{cm}^{-1}$ at $700^{\circ} \mathrm{C}$ ), demonstrating the high feasibil- 
ity of the double doping approach to enhance the ionic conductivity of stabilized bismuth oxides.

In this study, we developed $\mathrm{Tb}$ and $\mathrm{W}$ co-doped bismuth oxides. We selected $\mathrm{Tb}$ as a dopant since it has a slightly larger ionic radius and greater polarizability than Dy, thus expecting higher stability and conductivity compared to that of DWSB. ${ }^{7)}$

\section{Experimental Procedure}

\subsection{Preparation of electrolyte samples}

A flow chart of the sample preparation procedure is given in Fig. 1. The doped bismuth oxide powders with various compositions were developed via a typical solid-state reaction. In this study, we prepared 5 different compositions, including $\left(\mathrm{TbO}_{1.75}\right)_{\mathrm{x}}\left(\mathrm{BiO}_{1.5}\right)_{1-\mathrm{x}}($ where $\mathrm{x}=0.15,0.20$, and 0.25) and $\left(\mathrm{TbO}_{1.75}\right)_{\mathrm{x}}\left(\mathrm{WO}_{3}\right)_{\mathrm{y}}\left(\mathrm{BiO}_{1.5}\right)_{1-\mathrm{x}-\mathrm{y}}($ where $(\mathrm{x}, \mathrm{y})=(0.08,0.04)$, and $(0.10,0.05))$. The first three compositions with a single dopant $(\mathrm{Tb})$ are referred to as 15TSB, 20TSB, and 25TSB, respectively. The latter two samples, co-doped with $\mathrm{Tb}$ and $\mathrm{W}$ are referred to as $8 \mathrm{~T} 4 \mathrm{WSB}$ and 10T5WSB, respectively.

A stoichiometric mixture of $\mathrm{Bi}_{2} \mathrm{O}_{3}$ (99.9995\%), $\mathrm{Tb}_{4} \mathrm{O}_{7}$ (99.99\%) and $\mathrm{WO}_{3}(99.8 \%)$, from Alfa Aesar, were ballmilled with zirconia ball media for $24 \mathrm{~h}$. After milling, the powder mixtures were calcined at $800^{\circ} \mathrm{C}$ for $16 \mathrm{~h}$ and sieved with 325 mesh to achieve uniform particle sizes. The calcined powders were packed in a stainless steel die with 8 $\mathrm{mm}$ diameter and pressed uniaxially in the form of pellets under $40 \mathrm{MPa}$, and the subsequent cold isostatic pressing was performed at $200 \mathrm{MPa}$. The green bodies were sintered at $890^{\circ} \mathrm{C}$ for $16 \mathrm{~h}$ in ambient air. Au paste (Engelhard) was brush-painted to form electrodes on the surface of both sides

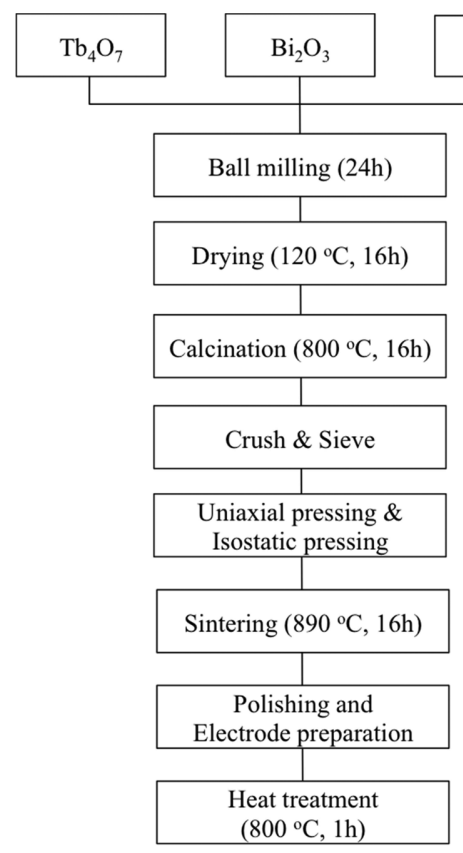

Fig. 1. Fabrication procedure of the Tb and $\mathrm{W}$ co-doped electrolyte samples. of the pellets and the electrodes were sintered at $800^{\circ} \mathrm{C}$ for $1 \mathrm{~h}$. For the current-collecting purpose, $\mathrm{Pt}$ wires were attached to both electrode surfaces.

\subsection{X-Ray diffraction analysis}

X-ray diffraction analysis (XRD, Philips APD 3720) was conducted to determine the crystal structure of the synthesized doped bismuth oxides using $\mathrm{CuK} \alpha 1$ radiation between $20^{\circ}$ and $70^{\circ}(2 \theta)$ at room temperature. For better lattice parameter estimation, the high temperature XRD (HTXRD, APD 3720 HT) from Philips was utilized under He gas in the temperature range from 25 to $700^{\circ} \mathrm{C}$. The contribution of $\mathrm{K} \alpha 2$ radiation was subtracted using the ProFit software (Philips).

\subsection{Conductivity measurements}

The total conductivity of the samples was measured by two-point probe electrochemical impedance spectroscopy (EIS) using a Solatron 1260 with an AC voltage amplitude of $10 \mathrm{mV}$ over the frequency range from $0.1 \mathrm{MHz}$ to $0.1 \mathrm{~Hz}$ in ambient air. Data acquisition was performed with $\mathrm{Z}$ plot software. To avoid artifacts from the lead wires and the equipment due to inductive responses, the resistance of the lead wires measured without a testing sample was subtracted from the measured data for each sample.

\section{Results and Discussion}

\subsection{Phase stability}

Figure 2 shows the XRD patterns of the singly doped specimens, including 15TSB, 20TSB, and 25TSB. Only 25TSB exhibited a pure cubic fluorite phase $\left(\delta-\mathrm{Bi}_{2} \mathrm{O}_{3}\right)$, while the bismuth oxides containing 15 and $20 \mathrm{~mol} \% \mathrm{~Tb}$ showed the coexistence of the majority of cubic and minor rhombohedral $\left(\mathrm{Bi}_{1.55} \mathrm{~Tb}_{0.45} \mathrm{O}_{3}\right)$ phases. Thus, this result indicates that the stabilization of the high conductivity cubic structure of bismuth oxides requires a $\mathrm{Tb}$ dopant concentration higher

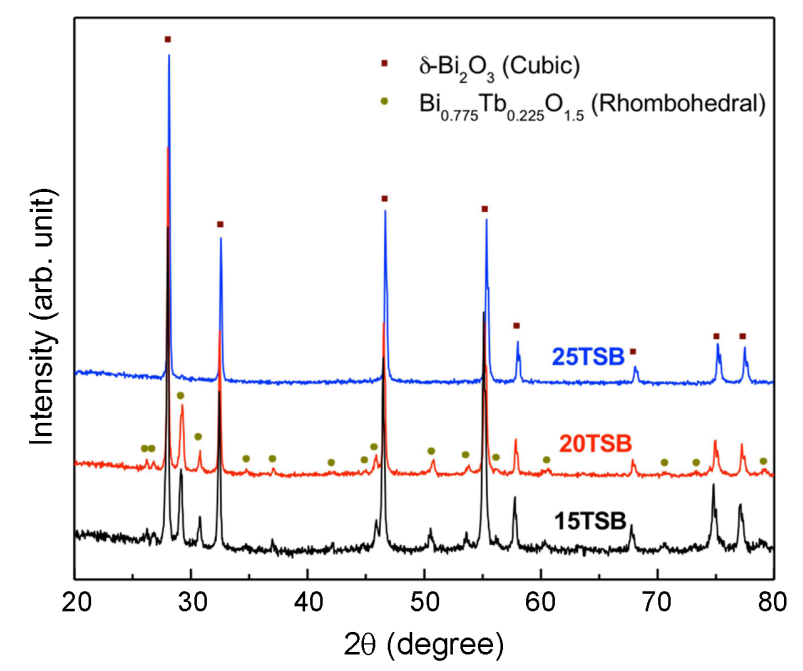

Fig. 2. XRD patterns of 15TSB, 20TSB, and 25TSB. 


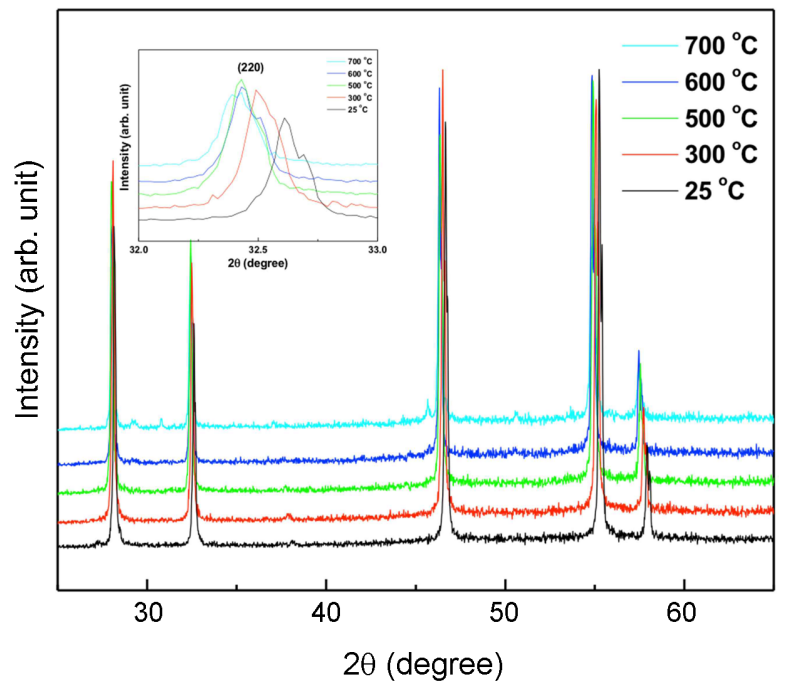

Fig. 3. HT-XRD patterns of $25 \mathrm{TSB}$ measured from 25 to $700^{\circ} \mathrm{C}$. Inset shows a magnified region at the range of $2 \theta$ angle from 32 to 33 degrees.

than $20 \mathrm{~mol} \%$. Previously, Esaka and Iwahara reported a similar result with the TSB system. ${ }^{20)}$ However, the minimum dopant concentration in their study (> $30 \mathrm{~mol} \% \mathrm{~Tb})$ is higher than that of our result ( $\sim 25 \mathrm{~mol} \% \mathrm{~Tb})$. Considering the meta-stable nature of the bismuth oxide phase at low dopant concentration, we attribute this deviation to different processing conditions during the calcination step along with different purities and morphologies of the initial powders.

The phase stability of 25TSB was observed using HT-XRD at the temperature range from 25 to $700^{\circ} \mathrm{C}$. The resultant XRD patterns are plotted in Fig. 3, indicating that the cubic phase was retained from room temperature to higher temperatures up to $700^{\circ} \mathrm{C}$, while a few minor impurity peaks were found at $700^{\circ} \mathrm{C}$.

From the HT-XRD data, the lattice parameters of the 25TSB at various temperatures were calculated by the extrapolation method using the Nelson-Riley function with the following equations: $:^{21)}$

$$
\begin{aligned}
& a=a_{0}+a_{0} K\left(\frac{\cos ^{2} \theta}{\sin \theta}+\frac{\cos ^{2} \theta}{\theta}\right) \\
& N=\frac{\cos ^{2} \theta}{\sin \theta}+\frac{\cos ^{2} \theta}{\theta}
\end{aligned}
$$

where $a, a_{0}, K$, and $N$ represent the apparent lattice parameter estimated from each peak position by Bragg's law, the true estimation of the lattice parameter, a constant, and the Nelson-Riley function, respectively. Fig. 4 shows the plots of the apparent measured parameters of 25TSB as a function of the Nelson-Riley function at $25,300,500$, and $600^{\circ} \mathrm{C}$. By extrapolation of each plot, the true lattice parameters $\left(a_{0}\right)$ are 5.527, 5.546, 5.570, and 5.578 $\AA$ at $25,300,500$, and $600^{\circ} \mathrm{C}$, respectively. The calculated values increase as temperature increases, indicating the thermal lattice expansion of 25TSB.

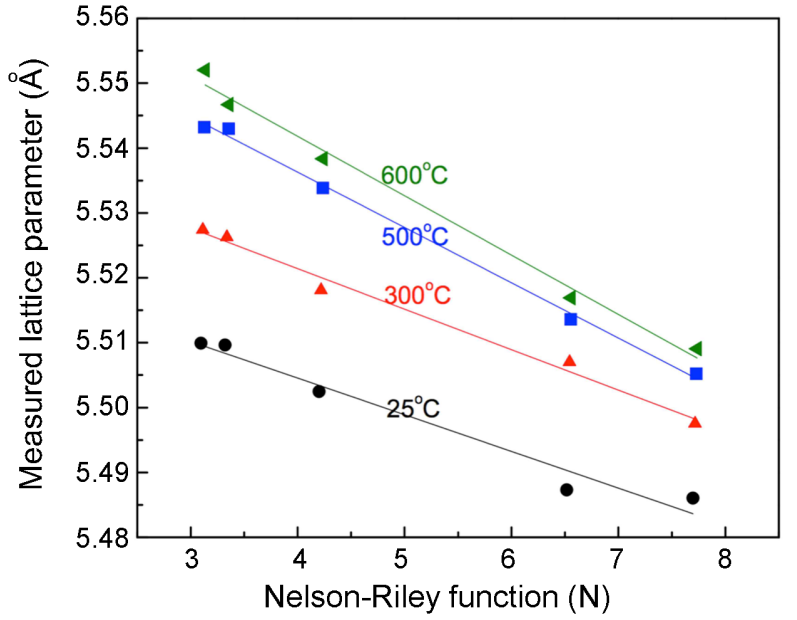

Fig. 4. Plots of the measured apparent lattice parameters as a function of the Nelson-Riley function at various temperatures.

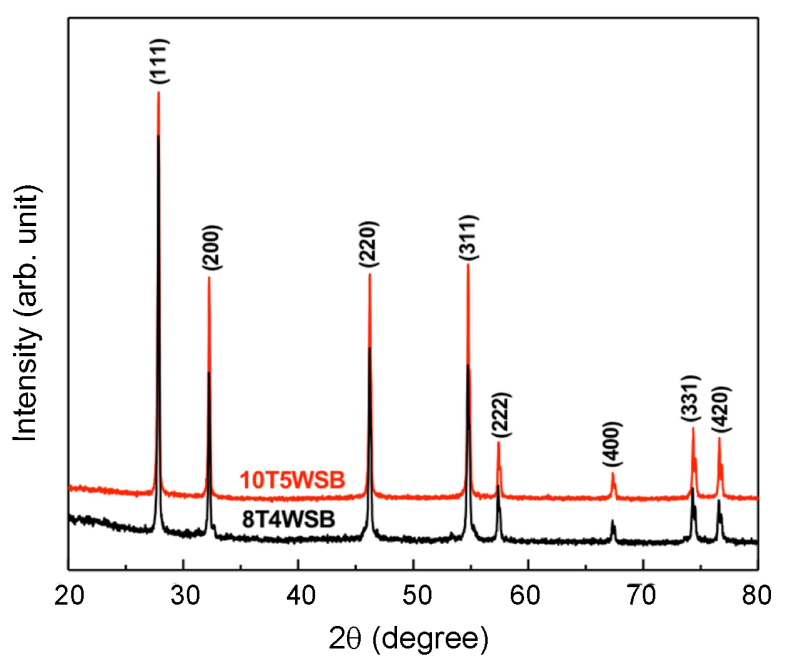

Fig. 5. XRD patterns of $8 \mathrm{~T} 4 \mathrm{WSB}$ and 10T5WSB.

Figure 5 shows the XRD results of 8T4WSB and 10T 5WSB. Both compositions exhibit the crystal structure of the cubic fluorite, although 8T4WSB has some minor impurity peaks. These results clearly demonstrate that the double dopant strategy, which we previously used for the Dy and $\mathrm{W}$ co-doped $\mathrm{Bi}_{2} \mathrm{O}_{3}$ system, effectively drops the total dopant concentration to stabilize the cubic $\delta-\mathrm{Bi}_{2} \mathrm{O}_{3}$ phase, thus expecting a higher conductivity with a lower total dopant concentration using a double dopant.

\subsection{Conductivity}

The conductivity of 25TSB and 10T5WSB was investigated via EIS measurement. Fig. 6 shows the resultant total conductivity as a function of inverse temperature for the measured samples in the temperature range from 300 to $700^{\circ} \mathrm{C}$. For reference, we compared our results with the conductivity of $20 \mathrm{~mol} \%$ Er-stabilized $\mathrm{Bi}_{2} \mathrm{O}_{3}$ (20ESB), and $8 \mathrm{D} 4 \mathrm{WSB}$ from the literature, ${ }^{19)}$ which are known as the 


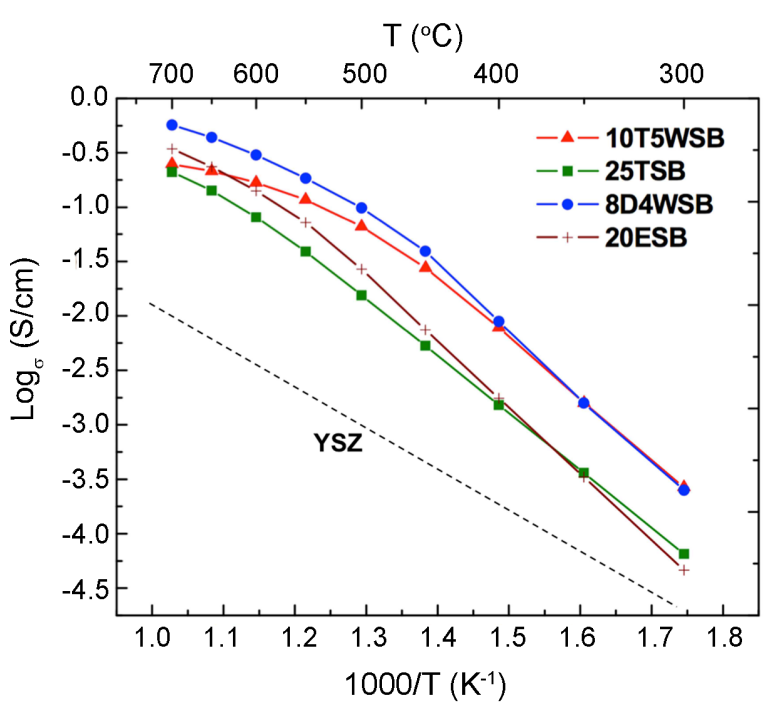

Fig. 6. Arrhenius plots of conductivities for 10T5WSB, 25TSB, 8D4WSB, ${ }^{17)} 20 \mathrm{ESB},{ }^{19)}$ and $\mathrm{YSZ}^{19)}$

highest conductivity compositions among the stabilized $\mathrm{Bi}_{2} \mathrm{O}_{3}$ systems with a single dopant and double dopants, ${ }^{17}$ ) respectively. Based on previous studies, we believe that all these conductivities are primarily ionic conductivity, while further investigation is needed to confirm it. As shown in Fig. 6, the trend of the initial conductivities $(\sigma)$ of these materials at temperatures between 400 to $600^{\circ} \mathrm{C}$ is clear:

$$
\sigma(8 \mathrm{D} 4 \mathrm{WSB})>\sigma(10 \mathrm{~T} 5 \mathrm{WSB})>\sigma(20 \mathrm{ESB})>\sigma(25 \mathrm{TSB}) .
$$

For example, the ionic conductivity values of $8 \mathrm{D} 4 \mathrm{WSB}$, $10 \mathrm{~T} 5 \mathrm{WSB}, 20 \mathrm{ESB}$, and $25 \mathrm{TSB}$ at $500^{\circ} \mathrm{C}$ are $0.0984,0.0634$,

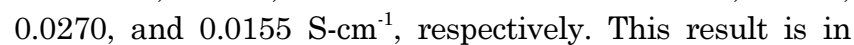
good agreement with the previously reported theory that the ionic conductivity of stabilized bismuth oxides with the cubic fluorite structure strongly depends on the total dopant concentration irrespective of the kind of dopants used..$^{13,22)}$

However, below $400^{\circ} \mathrm{C}$ the initial conductivity of 25TSB is higher than that of 20ESB. This phenomenon is attributed to higher linearity of activation energy of 25TSB without significant change at the measured temperature ranges, while 20ESB showed a large activation energy change between 500 to $600^{\circ} \mathrm{C}$ due to order-disorder transition. ${ }^{7)}$ For co-doped 10T5WSB, its conductivity was lower than that of $20 \mathrm{ESB}$ and $8 \mathrm{D} 4 \mathrm{WSB}$ at high temperatures $\left(>600^{\circ} \mathrm{C}\right)$, while it showed comparable conductivity at low temperatures $\left(<400^{\circ} \mathrm{C}\right)$.

\subsection{Long-term stability}

The long-term stability of 25TSB and 10T5WSB was investigated at $500^{\circ} \mathrm{C}$ for $\sim 100 \mathrm{~h}$. Fig. 7 shows the timedependent conductivity behavior of 25TSB and 10T5WSB in addition to that of $20 \mathrm{ESB}$ from the literature ${ }^{18)}$ with the isothermal operation condition at $500^{\circ} \mathrm{C}$ in ambient air. We found that 25TSB has fairly good long-term stability compared with other compositions, even though its initial con-

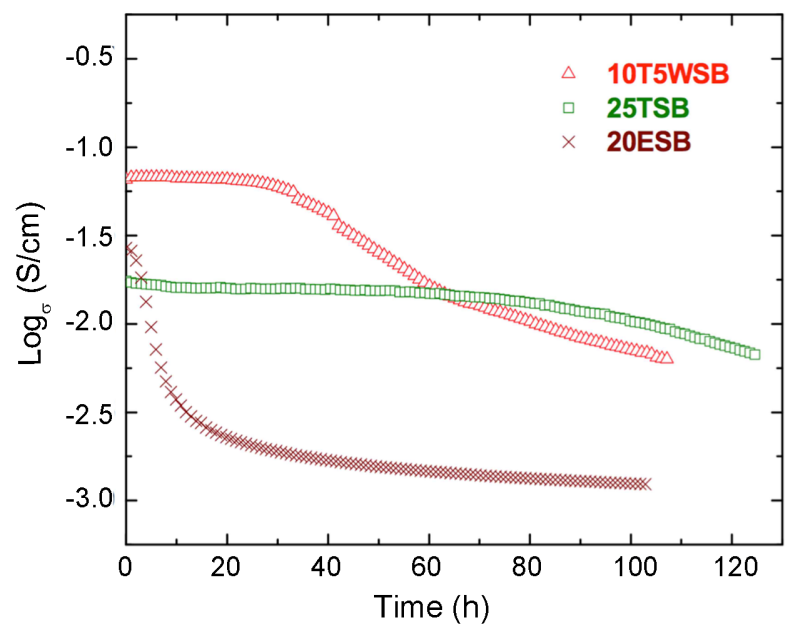

Fig. 7. Isothermal comparison of time-dependent conductivities of 10T5WSB, 25TSB, and 20ESB ${ }^{19)}$ annealed at $500^{\circ} \mathrm{C}$.

ductivity is relatively low while it experiences a small decrease in conductivity. The 10T5WSB sample has better initial conductivity than 20ESB and 25TSB due to its lower total dopant concentration as explained in the previous section, and it was considerably maintained for $35 \mathrm{~h}$ before gradual degradation occurred as a function of time. Therefore, we believe that, compared to 20ESB, larger dopants with high polarizability ( $\mathrm{Tb}$ and/or $\mathrm{W}$ ) are effective to suppress conductivity decay, as reported regarding other double-dopant (Dy and W)-stabilized bismuth oxides. ${ }^{17-19)}$

The phase stability of TSB and TWSB was determined via XRD analysis after a long-term stability test at $500^{\circ} \mathrm{C}$ for $\sim 100$ h. Fig. 8 shows a comparison of the XRD patterns of 25TSB and 10T5WSB before and after annealing. The 25TSB sample experienced cubic to rhombohedral phase transformation (Fig. 8(a)), which may be attributed to the small decrease in conductivity after $80 \mathrm{~h}$ as shown in Fig. 7. For 10T5WSB, the cubic phase was fairly well maintained, but the crystallinity was considerably reduced (Fig. 8(b)).Thus, in this case, the major conductivity degradation mechanism could be the order-disorder transition ${ }^{7)}$ combined with possible non-crystalline phase formation. Moreover, further stability testing under various temperatures for longer operation periods should be conducted for the practical application of these novel electrolyte materials.

\section{Conclusions}

In this study, we developed and investigated new doubledopant stabilized bismuth oxides with $\mathrm{Tb}$ and $\mathrm{W}$. With this double dopant strategy, the minimum dopant concentration to stabilize the cubic phase of bismuth oxides was effectively reduced. However, during long-term operation, TWSB showed a gradual decrease in conductivity and the crytallinity of its cubic phase was reduced. Thus, to develop novel SOFC electrolytes satisfying the demand for higher conduc- 

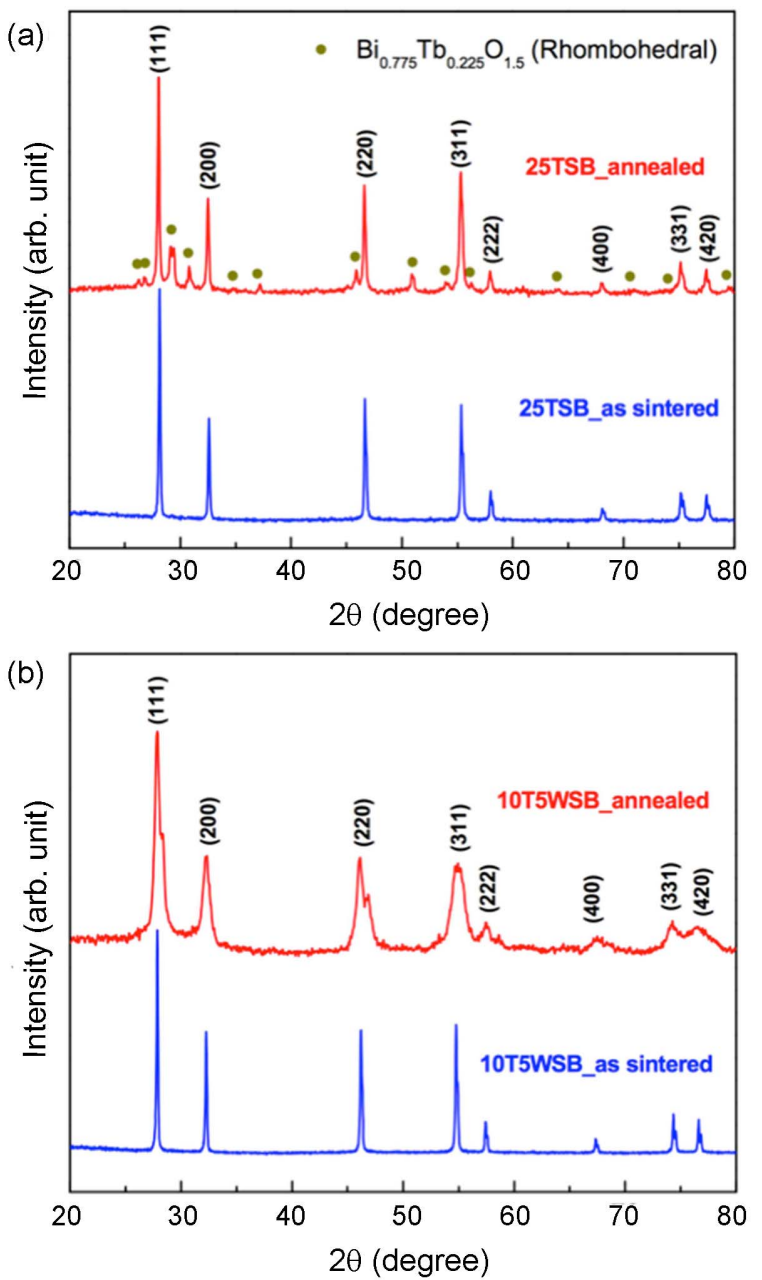

Fig. 8. XRD patterns of (a) 25TSB as-sintered and annealed at $500^{\circ} \mathrm{C}$ for $120 \mathrm{~h}$ and (b) $10 \mathrm{~T} 5 \mathrm{WSB}$ as-sintered and annealed at $500^{\circ} \mathrm{C}$ for $100 \mathrm{~h}$.

tivity as well as better long-term stability at reduced temperature, further investigation of the degradation mechanism and composition optimization of TWSB system is in progress.

\section{REFERENCES}

1. E. D. Wachsman and K. T. Lee, "Lowering the Temperature of Solid Oxide Fuel Cells," Science, 334 [6058] 935-39 (2011).

2. B. C. H. Steele and A. Heinzel, "Materials for Fuel-cell Technologies," Nature, 414 [6861] 345-52 (2001).

3. K. T. Lee, H. S. Yoon, and E. D. Wachsman, "The Evolution of Low Temperature Solid Oxide Fuel Cells," J. Mater. Res., 27 [16] 2063-78 (2012).

4. E. D. Wachsman, C. A. Marlowe, and K. T. Lee, "Role of Solid Oxide Fuel Cells in a Balanced Energy Strategy," Energy Environ. Sci., 5 [2] 5498-509 (2012).

5. S. B. Adler, "Factors Governing Oxygen Reduction in Solid Oxide Fuel Cell Cathodes," Chem. Rev., 104 [16] 4791-843 (2004).

6. S. Boyapati, E. D. Wachsman, and B. C. Chakoumakos,
"Neutron Diffraction Study of Occupancy and Positional Order of Oxygen Ions in Phase Stabilized Cubic Bismuth Oxides," Solid State Ionics, 138 [3-4] 293-304 (2001).

7. E. D. Wachsman, "Effect of Oxygen Sublattice Order on Conductivity in Highly Defective Fluorite Oxides," J. Eur. Ceram. Soc., 24 [6] 1281-85 (2004).

8. N. X. Jiang, E. D. Wachsman, and S. H. Jung, "A Higher Conductivity $\mathrm{Bi}_{2} \mathrm{O}_{3}$-based Electrolyte," Solid State Ionics, 150 [3-4] 347-53 (2002).

9. E. D. Wachsman, S. Boyapati, and N. Jiang, "Effect of Dopant Polarizability on Oxygen Sublattice Order in PhaseStable Cubic Bismuth Oxide," Ionics, 7 [1-2] 1-6 (2001).

10. N. Q. Minh, "Ceramic Fuel-cells," J. Am. Ceram. Soc., 76 [3] 563-88 (1993).

11. T. Takahashi, T. Esaka, and H. Iwahara, "Electrical-conduction in Sintered Oxides of System $\mathrm{Bi}_{2} \mathrm{O}_{3}-\mathrm{BaO}$," J. Solid State Chem., 16 [3-4] 317-23 (1976).

12. T. Takahashi, T. Esaka, and H. Iwahara, "High Oxide Ion Conduction in Sintered Oxides of System $\mathrm{Bi}_{2} \mathrm{O}_{3}-\mathrm{Gd}_{2} \mathrm{O}_{3}$," $J$ Appl. Electrochem., 5 [3] 197-202 (1975).

13. M. J. Verkerk and A. J. Burggraaf, "High Oxygen Ion Conduction in Sintered Oxides of the $\mathrm{Bi}_{2} \mathrm{O}_{3}-\mathrm{Dy}_{2} \mathrm{O}_{3}$ System," $J$. Electrochem. Soc., 128 [1] 75-82 (1981).

14. M. J. Verkerk, K. Keizer, and A. J. Burggraaf, "High Oxygen Ion Conduction in Sintered Oxides of the $\mathrm{Bi}_{2} \mathrm{O}_{3}-\mathrm{Er}_{2} \mathrm{O}_{3}$ System,” J. Appl. Electrochem., 10 [1] 81-90 (1980).

15. D. Mercurio, M. Elfarissi, B. Frit, J. M. Reau, and J. Senegas, "Fast Ionic-conduction in New Oxide Materials of the $\mathrm{Bi}_{2} \mathrm{O}_{3}-\mathrm{Ln}_{2} \mathrm{O}_{3}-\mathrm{TeO}_{2}$ Systems ( $\mathrm{Ln}=\mathrm{La}, \mathrm{Sm}, \mathrm{Gd}$, Er)," Solid State Ionics, 39 [3-4] 297-304 (1990).

16. G. Y. Meng, C. S. Chen, X. Han, P. H. Yang, and D. K. Peng, "Conductivity Of $\mathrm{Bi}_{2} \mathrm{O}_{3}$-based Oxide Ion Conductors With Double Stabilizers," Solid State Ionics, 28 [29-30] 533-38 (1988).

17. D. W. Jung, K. L. Duncan, and E. D. Wachsman, "Effect of Total Dopant Concentration and Dopant Ratio on Conductivity of $\left(\mathrm{DyO}_{1.5}\right)_{\mathrm{X}}-\left(\mathrm{WO}_{3}\right)_{\mathrm{Y}}-\left(\mathrm{BiO}_{1.5}\right)_{1-\mathrm{X}-\mathrm{Y}}$, " Acta Mater., 58 [2] 355-63 (2010).

18. D. W. Jung, J. C. Nino, K. L. Duncan, S. R. Bishop, and E. D. Wachsman, "Enhanced Long-term Stability of Bismuth Oxide-based Electrolytes for Operation at $500^{\circ} \mathrm{C}$," Ionics, 16 [2] 97-103 (2010).

19. D. W. Jung, K. L. Duncan, M. A. Camaratta, K. T. Lee, J. C. Nino, and E. D. Wachsman, "Effect of Annealing Temperature and Dopant Concentration on the Conductivity Behavior in $\left(\mathrm{DyO}_{1.5}\right)_{\mathrm{x}}-\left(\mathrm{WO}_{3}\right)_{\mathrm{y}}-\left(\mathrm{BiO}_{1.5}\right)_{1-\mathrm{x}-\mathrm{y}}$ ” J. Am. Ceram. Soc., 93 [5] 1384-91 (2010).

20. T. Esaka and H. Iwahara, "Oxide Ion and Electron Mixed Conduction in The Fluorite-type Cubic Solid-solution in The System $\mathrm{Bi}_{2} \mathrm{O}_{3}-\mathrm{Tb}_{2} \mathrm{O}_{3.5}$, J. Appl. Electrochem., 15 [3] 447-51 (1985).

21. J. B. Nelson and D. P. Riley, "An Experimental Investigation of Extrapolation Methods in The Derivation of Accurate Unit-cell Dimensions of Crystals," P. Phys. Soc. Lond., 57 [321] 160-77 (1945).

22. M. J. Verkerk and A. J. Burggraaf, "High Oxygen Ion Conduction in Sintered Oxides of the $\mathrm{Bi}_{2} \mathrm{O}_{3}-\mathrm{Ln}_{2} \mathrm{O}_{3}$ System," Solid State Ionics, 3-4 463-67 (1981). 